Proceedings

\title{
Comparison between Bioelectrical Impedance Analysis and Body Mass Index Methods in Determination of Obesity Preva- lence of Chinese Preschoolers ${ }^{\dagger}$
}

\author{
Qian Chen ${ }^{1}$, Zhiling Xie ${ }^{2}$, Shen $\mathrm{Ma}^{3}$ and Minxiong Chen ${ }^{2, *}$ \\ 1 Zhejiang Sports Science Institute, Hangzhou 310004, China; cq_chenqian@hotmail.com \\ 2 College of Physical Education and Health Sciences, Zhejiang Normal University, Jinhua 321004, Zhejiang, \\ China; zhiling_1699@163.com \\ 3 Physical Education Department, Zhejiang University of Water Resources and Electric Power, Hangzhou \\ 310018,Zhejiang, China; mashen@zjweu.edu.cn \\ * Correspondence: jhcmx@zjnu.cn; Tel.: +86-138-5798-9596
}

Publisher's Note: MDPI stays neutral with regard to jurisdictional

claims in published maps and institutional affiliations.

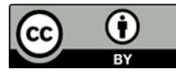

Copyright: (C) 2020 by the authors. Submitted for possible open access publication under the terms and conditions of the Creative Commons Attribution (CC BY) license (http://creativecommons.org/licenses /by/4.0/).

\begin{abstract}
Obesity has an increasing trend worldwide. Body mass index (BMI) is a common method of judging obesity, but the research of judging the appropriate bodyweight of Chinese children aged 3 to 6 years is still lacking. Bioelectrical impedance analysis (BIA) is a safe, accurate, reliable and inexpensive method for screening the overweight and obesity. In this study, preschool boys $(n=392)$ and girls $(n=309)$ aged 3 to 6 years, were recruited from kindergartens in Zhejiang province of China, completed a survey of BMI and BIA measured by InBody J20. Pearson correlation analysis of the correlation between BMI and BIA, and linear regression method analysis of BMI and BIA. The linear relationship between rates and construct a regression equation, using Kappa coefficient to test the consistency of BMI and body fat rate. The BMI of boys and girls decreased from 19.2 \pm 4.9 and $18.1 \pm 2.4$ at the age of 3 to $14.1 \pm 3.3$ and $15.1 \pm 3.3$ at the age of 6 , and showed a downward trend as the age increased. Analyzing the correlation between BMI and body fat percentage, it is 0.533 for boys and 0.539 for girls. The Kappa coefficient test results of BMI and body fat percentage showed that Kappa value $=0.339, \mathrm{P}<0.05$, indicating that the diagnostic results of $\mathrm{BMI}$ and body fat percentage were consistent, but the consistency was general.
\end{abstract}

Keywords: Body Fat Percentage; Body Mass Index; Bioelectrical Impedance Analysis; Obesity In Preschoolers

\section{Introduction}

Globally, the obesity epidemic has become a major public health problem, the number of school-age children and adolescents has nearly risen more than tenfold in just 40 years, from 11 million to 124 million[1]. BMI (Body Mass Index) is an indicator commonly used to judge whether the human body is obese, However, the use of BMI to assess body fat content is flawed [2]. First of all, height is an important part of the BMI calculation formula. Those children and adolescents or shorter adults will have a higher BMI, and BMI is also easy to confuse muscle and adipose tissue. Carpenter [3] also found that BMI is less sensitive to the detection of general obesity. There are few studies comparing the relationship between children's BMI and bioelectrical impedance. This study uses the bioelectrical impedance method to measure the consistency of the child's body fat rate and BMI in the diagnosis of childhood obesity, and provides a theory for the future development of diagnostic criteria for obesity in children aged 3-6 in accordance with. 


\section{Subjects and Methods}

\subsection{Subjects}

According to the random overall sampling method, 701 children aged 3 to 6 in 4 kindergartens in Hangzhou city of China, were tested for body shape and body fat, more information see table1.

Table 1. Years and gender distribution of sample.

\begin{tabular}{cccc}
\hline Years & Boys & Girls & Total \\
\hline 3 & 17 & 20 & 37 \\
3.5 & 39 & 20 & 59 \\
4 & 37 & 31 & 68 \\
4.5 & 74 & 51 & 125 \\
5 & 68 & 58 & 126 \\
5.5 & 68 & 53 & 121 \\
6 & 89 & 76 & 165 \\
Total & 392 & 309 & 701 \\
\hline
\end{tabular}

\subsection{Methods}

We use the InBodyJ20 produced by Best Company in South Korea to test the body composition of children. The test parameters include: height, weight, total body water, body fat, protein, inorganic salts, etc. Data collection time: May-July in 2019.

We use Pearson correlation to analyze the correlation between BMI and body fat rate, and use Kappa coefficient to test the consistency of BMI and body fat rate. The Kappa consistency test, that is, the level consistency test, is an examination of whether two ordinal variables have the same level. The Kappa value, that is, inter-rarer, coefficient of internal consistency, is an important indicator for evaluating the degree of consistency. When the Kappa value is between 0.8-1.0, the consistency of the two indicators is very good; when it is between 0.61-0.8, the consistency is good; when it is between 0.41-0.6, the consistency is medium; between 0.21-0.4 When between, the consistency is general; when between $0-0.2$, the consistency is poor; the Kappa value is equal to 0, indicating that the result of the diagnostic test is completely determined by random factors.

\section{Results}

\subsection{The Height, Body Weight and BMI of the Subjects}

Boys and girls have grown from $98.5 \pm 0.1 \mathrm{~cm}$ and $97.5 \pm 0.1 \mathrm{~cm}$ at the age of 3 to $119.6 \pm 0.1 \mathrm{~cm}$ and $118.6 \pm 0.1 \mathrm{~cm}$ at the age of 6 , respectively (table 2 ). There was a significant gender difference in height after the age $5(\mathrm{p}<0.05)$.

Table 2. Gender difference of height $(\bar{X} \pm \mathrm{SD}, \mathrm{cm})$.

\begin{tabular}{ccccc}
\hline Years & Boys & Girls & $\mathbf{t}$ & $\mathbf{p}$ \\
\hline 3 & $98.5 \pm 0.1$ & $97.5 \pm 0.1$ & -1.41 & 0.17 \\
3.5 & $102.2 \pm 0.1$ & $101.2 \pm 0.1$ & -0.82 & 0.42 \\
4 & $105.0 \pm 0.1$ & $106.3 \pm 0.1$ & 1.14 & 0.26 \\
4.5 & $109.4 \pm 0.1$ & $107.9 \pm 0.1$ & -1.93 & 0.06 \\
5 & $113.4 \pm 0.1$ & $110.4 \pm 0.1$ & -4.17 & 0.00 \\
5.5 & $116.6 \pm 0.1$ & $114.9 \pm 0.1$ & -2.00 & 0.04 \\
6 & $119.6 \pm 0.1$ & $118.6 \pm 0.1$ & -1.28 & 0.20 \\
Total & $112.0 \pm 0.1$ & $110.9 \pm 0.1$ & -2.00 & 0.04 \\
\hline
\end{tabular}

Boys and girls body weight have increased from $18.3 \mathrm{~kg}$ and $17.2 \mathrm{~kg}$ at the age of 3 to $20.1 \mathrm{~kg}$ and $21.1 \mathrm{~kg}$ at the age of 6 , respectively. There is no gender difference in the weight of boys and girls at all ages $(p>0.05$, table 3$)$. 
Table 3. Gender difference of body weight $\left(\bar{X}_{ \pm} \mathrm{SD}, \mathrm{kg}\right)$.

\begin{tabular}{ccccc}
\hline Years & Boys & Girls & $\mathbf{t}$ & $\mathbf{p}$ \\
\hline 3 & $18.3 \pm 2.7$ & $17.2 \pm 2.2$ & -1.3 & 0.20 \\
3.5 & $18.6 \pm 3.1$ & $18.9 \pm 3.0$ & 0.34 & 0.74 \\
4 & $21.1 \pm 4.2$ & $21.3 \pm 4.7$ & 0.18 & 0.86 \\
4.5 & $18.6 \pm 4.2$ & $18.3 \pm 3.6$ & -0.46 & 0.65 \\
5 & $21.4 \pm 4.0$ & $21.5 \pm 4.2$ & 0.09 & 0.93 \\
5.5 & $19.9 \pm 3.3$ & $20.1 \pm 3.4$ & 0.29 & 0.77 \\
6 & $20.1 \pm 4.4$ & $21.1 \pm 4.1$ & 1.50 & 0.14 \\
Total & $19.9 \pm 4.0$ & $20.2 \pm 4.0$ & 0.90 & 0.37 \\
\hline
\end{tabular}

The mean BMI for boys is $16.0 \mathrm{~kg} / \mathrm{m}^{2}$, and the mean for girls is $16.5 \mathrm{~kg} / \mathrm{m}^{2}$. For all the children, There is no gender difference between two groups ( $p>0.05)$. But for the 6-year-old group, there is a significant difference between boys and girls in $(\mathrm{p}<0.01)$. The BMI of children aged 3 6 years showed a general downward trend with age (table 4).

Table 4. Gender difference of BMI ( $\left.\bar{X}_{ \pm \mathrm{SD}}, \mathrm{kg} / \mathrm{m}^{2}\right)$.

\begin{tabular}{ccccc}
\hline Years & Boys & Girls & t & p \\
\hline 3 & $19.2 \pm 2.9$ & $18.1 \pm 2.4$ & -0.88 & 0.39 \\
3.5 & $17.9 \pm 3.1$ & $18.5 \pm 2.7$ & 0.69 & 0.49 \\
4 & $19.1 \pm 3.6$ & $18.9 \pm 4.3$ & -0.22 & 0.83 \\
4.5 & $15.6 \pm 3.7$ & $15.8 \pm 3.5$ & 0.26 & 0.80 \\
5 & $16.7 \pm 3.3$ & $17.7 \pm 3.7$ & 1.63 & 0.11 \\
5.5 & $14.7 \pm 2.6$ & $15.3 \pm 2.8$ & 1.17 & 0.25 \\
6 & $14.1 \pm 3.3$ & $15.1 \pm 3.3$ & 1.86 & 0.01 \\
Total & $16.0 \pm 3.8$ & $16.5 \pm 3.6$ & 1.78 & 0.08 \\
\hline
\end{tabular}

\subsection{Analysis of Body Composition of Children Aged 3 6}

The body composition of children aged 3 to 6 basically remained stable with the increase of age (table 5, table 6). But there is no gender difference, $\mathrm{P}>0.05$.

Table 5. Body composition of boys aged 3 6 ( $\left.\bar{X}_{ \pm \mathrm{SD}}, \mathrm{n}=392\right)$.

\begin{tabular}{cccccccc}
\hline Year & $\mathbf{3}$ & $\mathbf{3 . 5}$ & $\mathbf{4}$ & $\mathbf{4 . 5}$ & $\mathbf{5}$ & $\mathbf{5 . 5}$ & $\mathbf{6}$ \\
\hline Body fat (kg) & $4.5 \pm 1.7$ & $4.9 \pm 1.7$ & $5.1 \pm 2.7$ & $4.0 \pm 2.3$ & $4.7 \pm 2.4$ & $4.5 \pm 2.0$ & $4.6 \pm 2.5$ \\
Fat free (kg) & $13.8 \pm 1.0$ & $13.8 \pm 1.8$ & $16.0 \pm 2.2$ & $14.6 \pm 2.6$ & $16.7 \pm 2.5$ & $15.5 \pm 2.1$ & $15.5 \pm 2.6$ \\
Muscles (kg) & $6.4 \pm 0.6$ & $6.4 \pm 1.1$ & $7.7 \pm 1.4$ & $6.7 \pm 1.6$ & $8.1 \pm 1.7$ & $7.3 \pm 1.5$ & $7.4 \pm 1.7$ \\
Minerals (kg) & $0.7 \pm 0.1$ & $0.6 \pm 0.1$ & $0.8 \pm 0.1$ & $0.7 \pm 0.2$ & $0.9 \pm 0.2$ & $0.8 \pm 0.2$ & $0.8 \pm 0.2$ \\
$\begin{array}{c}\text { Intracellular flu- } \\
\quad \text { id (L) }\end{array}$ & $6.4 \pm 0.5$ & $6.5 \pm 0.9$ & $7.4 \pm 1.1$ & $6.9 \pm 1.2$ & $7.7 \pm 1.3$ & $7.2 \pm 1.2$ & $7.2 \pm 1.3$ \\
$\quad \begin{array}{c}\text { Extracellular } \\
\text { fluid (L) }\end{array}$ & $3.9 \pm 0.3$ & $3.9 \pm 0.5$ & $4.5 \pm 0.6$ & $4.1 \pm 0.7$ & $4.7 \pm 0.8$ & $4.4 \pm 0.6$ & $4.4 \pm 0.8$ \\
Body water (L) & $10.3 \pm 0.7$ & $10.4 \pm 1.4$ & $12.0 \pm 1.7$ & $11.0 \pm 1.9$ & $12.5 \pm 2.1$ & $11.5 \pm 1.8$ & $11.6 \pm 2.0$ \\
$\quad$ Protein (kg) & $2.8 \pm 0.2$ & $2.8 \pm 0.4$ & $3.2 \pm 0.5$ & $3.0 \pm 0.5$ & $3.3 \pm 0.6$ & $3.1 \pm 0.5$ & $3.1 \pm 0.6$ \\
\hline
\end{tabular}

Table 6. Body composition of girls aged 3 6 ( $\left.\bar{X}_{ \pm} \mathrm{SD}, \mathrm{n}=309\right)$.

\begin{tabular}{cccccccc}
\hline Year & $\mathbf{3}$ & $\mathbf{3 . 5}$ & $\mathbf{4}$ & $\mathbf{4 . 5}$ & $\mathbf{5}$ & $\mathbf{5 . 5}$ & $\mathbf{6}$ \\
\hline Body fat $(\mathrm{kg})$ & $4.2 \pm 1.0$ & $4.7 \pm 1.6$ & $5.6 \pm 3.2$ & $3.8 \pm 1.7$ & $5.0 \pm 2.5$ & $4.7 \pm 2.1$ & $4.9 \pm 2.5$ \\
Fat free $(\mathrm{kg})$ & $13.0 \pm 1.5$ & $14.2 \pm 1.7$ & $15.7 \pm 2.1$ & $14.5 \pm 2.5$ & $16.5 \pm 2.6$ & $15.4 \pm 2.1$ & $16.2 \pm 2.5$ \\
\hline
\end{tabular}




\begin{tabular}{cccccccc}
\hline Muscles (kg) & $6.0 \pm 0.9$ & $6.7 \pm 1.0$ & $7.5 \pm 1.4$ & $6.9 \pm 1.6$ & $8.0 \pm 1.6$ & $7.4 \pm 1.3$ & $7.9 \pm 1.6$ \\
Minerals (kg) & $0.6 \pm 0.1$ & $0.7 \pm 0.1$ & $0.8 \pm 0.2$ & $0.7 \pm 2.0$ & $0.8 \pm 0.2$ & $0.8 \pm 0.1$ & $0.8 \pm 0.2$ \\
$\begin{array}{c}\text { Intracellular flu- } \\
\quad \text { id (L) }\end{array}$ & $6.1 \pm 0.7$ & $6.7 \pm 0.8$ & $7.3 \pm 1.1$ & $6.8 \pm 1.2$ & $7.7 \pm 1.2$ & $7.2 \pm 1.0$ & $7.6 \pm 1.2$ \\
$\quad \begin{array}{c}\text { Extracellular } \\
\text { fluid (L) }\end{array}$ & $3.7 \pm 0.4$ & $4.0 \pm 0.5$ & $4.4 \pm 0.6$ & $4.1 \pm 0.7$ & $4.7 \pm 0.7$ & $4.4 \pm 0.6$ & $4.6 \pm 0.7$ \\
Body water (L) & $9.8 \pm 1.1$ & $10.7 \pm 1.2$ & $11.7 \pm 1.7$ & $10.9 \pm 1.8$ & $12.4 \pm 2.0$ & $11.6 \pm 1.6$ & $12.1 \pm 1.9$ \\
$\quad$ Protein (kg) & $2.6 \pm 0.3$ & $2.9 \pm 0.3$ & $3.1 \pm 0.5$ & $2.9 \pm 0.5$ & $3.3 \pm 0.6$ & $3.1 \pm 0.4$ & $3.3 \pm 0.5$ \\
\hline
\end{tabular}

There is no gender difference in the body fat percentage of boys and girls (table7, $p=0.328, p>0.05$ ), the body fat percentage of children aged 3 to 4 is higher than that of 4.5 to 6 years old, and the difference is statistically significant $(\mathrm{p}<0.01)$. The percentage of body fat of children aged 3-6 years shows a downward trend with age (Figure1).

Figure 1 and Figure 2 show BMI and body fat percentage have the same downward trend with age.

Table 7. Gender difference of body fat percentage $\left(\bar{X}_{ \pm S D}, \%\right)$.

\begin{tabular}{ccccc}
\hline Years & Boys & Girls & t & p \\
\hline 3 & $24.0 \pm 5.8$ & $24.2 \pm 3.3$ & 0.14 & 0.89 \\
3.5 & $25.6 \pm 5.4$ & $24.3 \pm 4.6$ & -0.96 & 0.34 \\
4 & $23.1 \pm 7.5$ & $25.0 \pm 8.5$ & 1.00 & 0.32 \\
4.5 & $20.5 \pm 7.3$ & $20.1 \pm 7.1$ & -0.37 & 0.71 \\
5 & $21.2 \pm 7.2$ & $22.5 \pm 7.3$ & 0.96 & 0.34 \\
5.5 & $21.8 \pm 7.0$ & $22.7 \pm 7.1$ & 0.68 & 0.49 \\
6 & $21.9 \pm 7.1$ & $22.5 \pm 7.2$ & 0.58 & 0.56 \\
Total & $22.1 \pm 7.1$ & $22.6 \pm 7.1$ & 0.98 & 0.76 \\
\hline
\end{tabular}

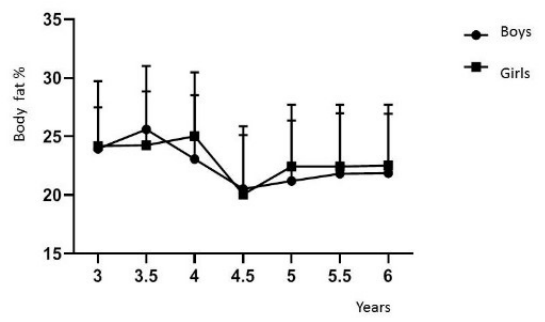

Figure 1. Body fat percentage of children aged $3 \sim 6$.

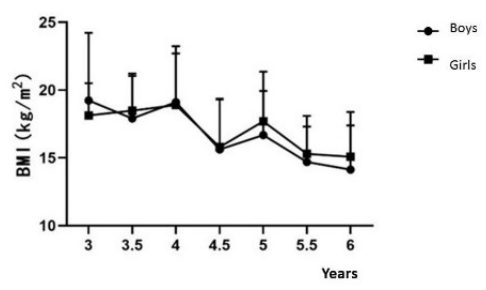

Figure 2. BMI in Children aged 3 6.

\subsection{Kappa Coefficient Consistency Test}

Analyzing the correlation between BMI and body fat percentage, it is 0.533 for boys and 0.539 for girls $(\mathrm{p}<0.05)$. Kappa is an important indicator of inter-rarer and coefficient of internal consistency, The consistency test results of the Kappa coefficient of BMI and body fat percentage showed that Kappa value $=0.339, \mathrm{P}<0.05$ (Table 8), indicating 
that the diagnostic results of BMI and body fat percentage were consistent, but the Kappa value was between $0.21-0.4$, and the consistency was general.

Table 8. Kappa coefficient consistency test for BMI and BIA body fat.

\begin{tabular}{ccccc}
\hline & value & $\begin{array}{c}\text { Asymptotic stand- } \\
\text { ard error }\end{array}$ & approximation & $p$ \\
\hline Kappa & 0.339 & 0.042 & 11.108 & 0.00 \\
$\mathrm{n}$ & 701 & & & \\
\hline
\end{tabular}

\section{Discussion}

Zhao et al. [4] found BMI is a more reliable for predicting body fat indicator predicting adiposity in children. Unlike adults, BMI during childhood are generally attributed to the lean rather than to the fat component of BMI [5]. Our finding may aid future obesity monitoring and intervention in children, we may need multiple methods to measure and evaluate childhood obesity. We should combine BIA and BMI for screening obesity and overweight in young adults [6].

Author Contributions: Conceptualization, Q.C.; methodology, S.M.; writing-review and editing, Y.Z.; supervision, M.C.; project administration, Q.C.; funding acquisition, M.C. All authors have read and agreed to the published version of the manuscript.

Funding: This study was supported by the grant (18YJA890017) from Humanities and Social Science Research Fund Project of China Education Ministry. The authors are thankful to Zhejiang Normal University for the support.

Conflicts of Interest: The authors declare no conflict of interest.

\section{References}

1. Lim H J, Xue H, Wang Y. Global Trends in Obesity[J]. Handbook of Eating and Drinking: Interdisciplinary Perspectives. 2020: 1217-1235.

2. Shah N R, Braverman E R. Measuring adiposity in patients: the utility of body mass index (BMI), percent body fat, and leptin[J]. PloS one. 2012, 7(4): e33308.

3. Carpenter C L, Yan E, Chen S, et al. Body fat and body-mass index among a multiethnic sample of college-age men and women[J]. Journal of obesity. 2013, 2013.

4. Zhao D, Zhang Y. Body mass index (BMI) predicts percent body fat better than body adiposity index (BAI) in school children[J]. Anthropologischer Anzeiger. 2015, 72(3): 257-262.

5. Maynard L M, Wisemandle W, Roche A F, et al. Childhood body composition in relation to body mass index[J]. Pediatrics. 2001, 107(2): 344-350.

6. Hung S, Chen C, Guo F, et al. Combine body mass index and body fat percentage measures to improve the accuracy of obesity screening in young adults[J]. Obesity research \& clinical practice. 2017, 11(1): 11-18. 